\title{
Colorectal carcinogenesis: an archetype of gut microbiota-host interaction
}

\author{
James L Alexander, Alasdair J Scott, Anna L Pouncey, Julian Marchesi, James Kinross and Julian Teare \\ Centre for Digestive and Gut Health, Department of Surgery and Cancer, Imperial College London, 10th Floor QEQM Building, St Mary's Hospital, South \\ Wharf Road, London W2 1NY, UK
}

Correspondence to: James Kinross. Email: j.kinross@imperial.ac.uk

\begin{abstract}
Sporadic colorectal cancer (CRC) remains a major cause of worldwide mortality. Epidemiological evidence of markedly increased risk in populations that migrate to Western countries, or adopt their lifestyle, suggests that CRC is a disease whose aetiology is defined primarily by interactions between the host and his environment. The gut microbiome sits directly at this interface and is now increasingly recognised as a modulator of colorectal carcinogenesis. Bacteria such as Fusobacterium nucleatum and Escherichia coli (E. Coli) are found in abundance in patients with CRC and have been shown in experimental studies to promote neoplasia. A whole armamentarium of bacteria-derived oncogenic mechanisms has been defined, including the subversion of apoptosis and the production of genotoxins and pro-inflammatory factors. But the microbiota may also be protective: for example, they are implicated in the metabolism of dietary fibre to produce butyrate, a short chain fatty acid, which is anti-inflammatory and anti-carcinogenic. Indeed, although our understanding of this immensely complex, highly individualised and multi-faceted relationship is expanding rapidly, many questions remain: Can we define friends and foes, and drivers and passengers? What are the critical functions of the microbiota in the context of colorectal neoplasia?
\end{abstract}

Keywords: colorectal cancer, microbiota, fusobacterium, metabolic function, interaction

Published: 05/09/2018

Received: 05/03/2018

ecancer 2018, 12:865 https://doi.org/10.3332/ecancer.2018.865

Copyright: (C) the authors; licensee ecancermedicalscience. This is an Open Access article distributed under the terms of the Creative Commons Attribution License (http://creativecommons.org/licenses/by/3.0), which permits unrestricted use, distribution, and reproduction in any medium, provided the original work is properly cited. 


\section{Introduction}

By recent estimates, almost a quarter of a million Europeans are diagnosed with colorectal cancer (CRC) annually, and incidence is rising [1]. Perhaps, more concerning, since 1998, in contrast to the declines seen in older patients, younger adults have experienced an apparent increase in the incidence of CRC [2]. Indeed, although CRC is predominantly a disease of later age in the West (median age at diagnosis approximately 70 years [3]), the age-specific relative risk has been increasing in younger generations over recent decades, meaning that adults born in the USA in 1990 have double the risk of colon cancer and quadruple the risk of rectal cancer compared to those born in 1950 [4].

Traditional models of cancer aetiology have focussed on understanding how mammalian genetic susceptibility combines with risk factors such as smoking to drive carcinogenesis. As a contributor to disease pathogenesis, the gut microbiota (namely, the bacteria, viruses, archaea and eukaryotic organisms that inhabit the human gastrointestinal tract) had largely hidden in the blind spot of the medical research community until the last 10 years. This was fundamentally a technological issue: the culture-based methods previously used to study bacteria (still the mainstay of clinical microbiology laboratories) are not well suited to the large-scale analysis of the cornucopia microorganisms present in the large intestine. But with the advent of next-generation sequencing, there has been a paradigm shift in our ability to catalogue and characterise this ecosystem [5]. There has followed a rapid proliferation of interest in this so-called 'forgotten organ' and the development of the Human Microbiome Project, which attempted to database the microbiota in much the same way that geneticists had done with the human genome years earlier [6]. In this review, we discuss how the rapid development in the knowledge of the gut microbiome is providing novel insights into colorectal carcinogenesis.

\section{Diet, lifestyle, the gut microbiome and CRC}

CRC rates vary by up to 10 -fold around the world. The majority of cases and deaths occur in countries with high or very high human development indices [7]. Low- and middle-income countries transitioning quickly towards a more westernised society and economy exhibit the starkest increases in incidence [8]. Examples include Brazil and Bulgaria, with average annual percentage changes in the incidence of 7.2 and 3.6, respectively [7]. Given the rapidity of this trend, there is a compelling argument for the pre-eminent contribution of lifestyle factors over host genetics in the pathogenesis of this disease. Indeed, family history of CRC accounts for only a small proportion of the variation [9]. Established risk factors include alcohol [10], lack of physical activity [11], smoking [12], obesity [13] and perhaps most importantly, diet.

The observation that diet might influence the risk of gastrointestinal diseases such as CRC is historic-Burkitt made the link to dietary fibre depletion in the 1970s [14]; although the existing data with regard to fibre intake are somewhat conflicting [15, 16]. There is now a body of evidence pointing to high intake of red and processed meat as an integral player in CRC risk [17-20].

Compelling evidence for diet's importance comes from migrant studies which have shown that within one generation, immigrant populations adopt the colon cancer incidence of the host Western population [21]. Despite this observation, genome-wide association studies have required very large cohorts of subjects to demonstrate the significant linkage between loci that influence CRC risk and diet, suggesting that another factor is at play $[22,23]$. The microbiota have been implicated in the metabolism of red meat derivatives and the consequent production of choline, trimethylamine and hydrogen sulphide, all of which may be deleterious to host health [24-26]. Much work has centred on the microbial metabolism of fibre, which is relatively deficient in the Western diet [27]. There is considerable evidence that fibre fermentation products, such as the short chain fatty acids (SCFAs), which are essential energy sources for normal colonocytes, also dampen inflammatory processes and are anti-carcinogenic [28, 29]. For example, one such SCFA, butyrate, has been shown to down-regulate the canonical Wnt-signalling pathway [30], inhibit cancerous colonocyte proliferation through histone deacetylase inhibition [31] and induce apoptosis [32]. Studies have shown a reduction in butyrate-producing phyla in the microbiomes of animal models and patients with CRC [33-35].

Studies comparing African Americans and rural Africans perhaps best support the role of the gut microbiota as a mediator of diet-induced cancer risk [36]. The work of O'Keefe and co-workers demonstrated that the diets of African Americans living in Pittsburgh were dominated by fat and processed meat, in contrast to those of rural South Africans, which were dominated by fibre [37]. African Americans, who are at high risk of $\mathrm{CRC}$, have colons predominated by Prevotella species, while rural Africans, with low risk of CRC, are colonised by Bacteroides species. When these diets were switched, rapid reciprocal shifts in the microbiota and metabolomes of the groups were accompanied by marked changes in mucosal biomarkers of cancer risk. The conclusion from this work is that a change in bacterial co-occurrences 
across niche-specific microbial networks associated with symbiotic metabolism of dietary nutrients pre-conditions the gut into either a prooncogenic or protective state. The relative absence of Fusobacterium nucleatum (an organism with links to CRC which we will discuss in greater detail) in CRCs from patients with high-fibre diets supports this hypothesis [38].

In addition to dietary patterns, migration changes many other aspects of the environment and there is now evidence that the microbiome is at least modified by CRC risk factors such as smoking [39, 40], exercise [41, 42] and alcohol [43]. There is also evidence that differences in host genotype affect the carbohydrate landscape of the distal gut and these in turn interact with the diet to alter the composition and function of resident microbes in a diet-dependent manner. Therefore, it is possible that patients genetically predisposed to CRC have a modified metabolically active microbiome, which is not only determined by their genes but also by their family environment, dietary habits and lifestyle choices.

\section{Inflammation, obesity, CRC and the microbiota}

A unifying issue in the pathogenesis of CRC is the presence of persistent low-grade inflammation. This is supported by evidence that cancer risk may be reduced by greater than a quarter by anti-inflammatory drugs [44]. A large proportion of morbidly obese individuals $(30 \%-70 \%)$ gets CRC, and obesity is characterised by systemic low-level inflammation [45]. Metataxonomic studies have demonstrated elevated numbers of Firmicutes and decreased levels of Bacteroidetes and a reduced microbial diversity and genetic abundance in obese individuals [46]. It is therefore feasible that cancer in the colon is driven by particular microbes that are fostered in an obese-related inflammatory environment.

Bariatric surgery presents a useful opportunity for studying the impact of the gut microbiota on host metabolic function, and gastric bypass surgery has a profound impact on the distal microbiome construct and its metabolic function $[47,48]$. It is interesting to note, therefore, the paradox in patients undergoing bariatric surgical procedures, where epidemiological evidence suggests the risk of CRC in fact increases [49] and patients have poorer outcomes [50]. Evidence from post gastric bypass murine models has also demonstrated that the faecal stream, which is partly a product of microbiota-mediated metabolism of dietary substrates, is highly genotoxic [51]. This suggests that the relationship between obesity and CRC may be modulated by the microbiota, and that surgical bariatric interventions may inadvertently alter an individual's CRC risk by driving the microbiota towards a pro-carcinogenic state.

\section{The case for an oncogenic driver species in CRC}

The concept that microbes might be pathogenic mediators of neoplasia is, of course, not novel. In the 1980s, Helicobacter pylori was identified in the stomach of patients with gastritis and peptic ulceration, providing a link between the bacterium and gastric cancer [52]. The initial hostile response of the scientific community to this, now well-established, association is perhaps instructive [53]. The human papillomavirus virus is relatable to the vast majority of cervical cancers, as well as some anal, vulvar and oropharyngeal neoplasms [54]. Liver fluke infections are strongly associated with cholangiocarcinoma in East Asia $[55,56]$ and chronic infection with the parasite Shistosoma haematobium predisposes carriers to urothelial malignancy [57]. With the colon hosting the great majority of microbiota residing in the human body [58], it is only logical that investigators have sought to make similar discoveries with regard to CRC.

With the examples from other body sites in mind, research to date on the gut microbiota has attempted to define specific microbial candidates that serve as 'alpha bacteria' or pro-oncogenic driver species in CRC [59]. On this basis, the evidence is now available for a stable of bacteria with mechanistic plausibility as aetiological agents in CRC (Table 1 and Figure 1).

The gram-negative anaerobe Fusobacterium nucleatum has been associated with carcinomas and adenomas of the colon and rectum in a number of human studies [60-65]. F. nucleatum was typically regarded as an oral commensal bacterium and has a relatively low abundance in the healthy human colon [66]. It has long been recognised as one of the principal pathogens in gingivitis and periodontitis, and it is from this setting that biologically plausible mechanisms of colorectal oncogenesis first emerged [67]. In an in vitro model, its fadA adhesin was shown to bind to E-cadherin on CRC cell lines resulting in invasion by the organism and activation of the $\beta$-catenin/Wnt signalling cascade with consequent stimulation of cell proliferation [68]. Furthermore, fadA gene and protein expression were increased in adenomas and adenocarcinomas compared to healthy mucosa from non-tumorous individuals, and correlated with significantly raised expression of Wnt genes, consistent with the in vitro data. 
Table 1. Bacteria with evidence of pro-oncogenic mechanisms in experimental studies of CRC.

\begin{tabular}{|c|c|}
\hline Bacterium & Proposed pro-oncogenic mechanisms \\
\hline Streptococcus gallolyticus [95-97] & $\begin{array}{l}\text { - COX-2 mediated inflammatory response } \\
\text { - Beta-catenin dependent cell proliferation }\end{array}$ \\
\hline Enterococcus faecalis $[98,99]$ & $\begin{array}{l}\text { Bystander effect: Induction of mucosal macrophages to pro- } \\
\text { duce clastogens that cause DNA damage through free radical } \\
\text { and superoxide production }\end{array}$ \\
\hline E. Coli $[76,78,100,101]$ & $\begin{array}{l}\text { - Toxin production: genotoxin Colibactin breaks double-stranded } \\
\text { DNA } \\
\text { - Genotoxicity induced by OMVs } \\
\text { - Depletion of host mismatch repair proteins via bacterially } \\
\text { secreted EspF effector protein }\end{array}$ \\
\hline Bacteroides fragilis [102-105] & $\begin{array}{l}\text { Inflammatory stimulus leads to increased reactive oxygen } \\
\text { species production and DNA damage resulting from spermine } \\
\text { oxidase polyamine catabolism } \\
\text { - Stat3 activation of mucosal IL-17 response }\end{array}$ \\
\hline Fusobacterium nucleatum $[61,68,69,72]$ & $\begin{array}{l}\text { Modulation of E-cadherin/B-catenin signalling via FadA } \\
\text { adhesion } \\
\text { - Recruitment of proinflammatory myeloid cells conducive to } \\
\text { tumour progression } \\
\text { - Tumour-immune evasion via Fap2 protein inhibition of NK cell } \\
\text { cytotoxicity }\end{array}$ \\
\hline Peptostreptococcus anaerobius [106] & $\begin{array}{l}\text { Increased levels of reactive oxygen species promote choles- } \\
\text { terol synthesis and cell proliferation }\end{array}$ \\
\hline Helicobacter hepaticus [107] & $\begin{array}{l}\text { - Up-regulation of tissue inducible Nitric Oxide Synthase and } \\
\text { TNF-alpha }\end{array}$ \\
\hline
\end{tabular}

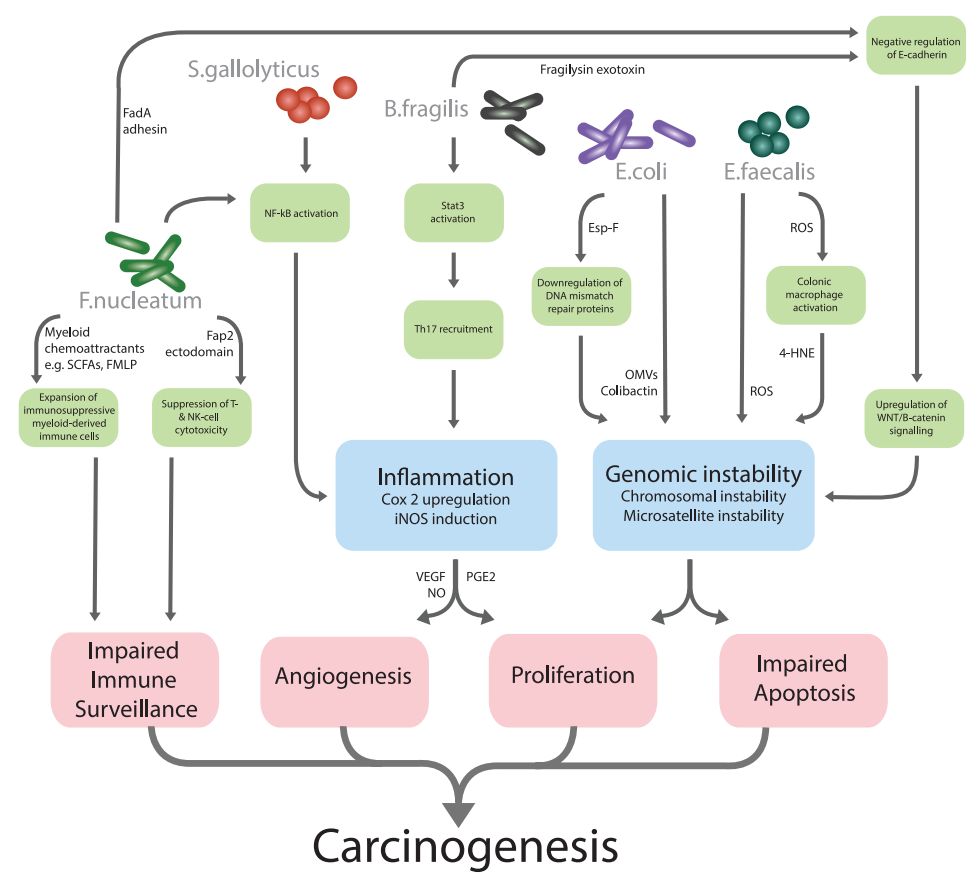

Figure 1. Gut microbiota and their mechanistic links to colorectal carcinogenesis. 
Further support for a tumorigenic role of $F$. nucleatum is provided by a series of experiments in which Apc $\mathrm{Min} /+^{\mathrm{mice}}$, which develop gastrointestinal tumours, were exposed to a $F$. nucleatum strain isolated from a patient with inflammatory bowel disease. Exposure resulted in a significant increase in the numbers of colonic tumours and, in accord with human data, $F$. nucleatum was enriched in tumour tissue relative to adjacent normal mucosa [61]. Interestingly, F. nucleatum did not induce colitis in the Apc ${ }^{\mathrm{Min} /+}$ mice, which contrasts with the known mechanism of accelerated tumorigenesis induced by enterotoxigenic $B$. fragilis in the same model. Rather, the authors found that $F$. nucleatum recruited tumour-permissive immune cells to the murine tumour microenvironment, which potentiated tumour progression. Similarly, the expression of relevant immune cell marker genes positively correlated with Fusobacterium spp. abundance in human CRC specimens. In another study, the F. nucleatum Fap2 ectodomain inhibited human natural killer (NK) cell anti-tumour toxicity via the TIGIT receptor which is expressed on all T cells, permitting evasion of tumour cells from immune surveillance [69]. F. nucleatum has also been shown to activate TLR-4 signalling to MYD88, leading to activation of Nuclear Factor-kB via increased expression of microRNA21 (miR21) [70]. Collectively, these experimental data support an association between F. nucleatum and human CRC and provide plausible mechanisms for promoting oncogenesis directly, via activation of Wnt and, indirectly, by dampening of host anti-tumour immune responses.

Importantly, there is now evidence from human populations that the presence of Fusobacteria may be of prognostic importance, as it is associated with CIMP positivity, TP53 wild-type, hMLH1 methylation positivity, MSI and CHD7/8 mutation positivity [71]. Mima and coworkers found that $F$. nucleatum was associated with a lower density of CD3+ T cells, which have an important role in the anti-CRC adaptive immune response, conferring better prognosis [72]. The same investigators also found that the amount of $F$. nucleatum DNA in CRC tissue is associated with shorter patient survival [73] and intriguingly, there is evidence emerging that the organism persists and migrates in metastatic deposits, distant from the primary tumour [74].

E. Coli is another common organism found to be over-represented on CRC mucosa [75]. E. coli promotes tumour growth, both in vitro and in a xenograft model, via its genotoxin colibactin [76] and expresses genes that are known to have oncogenic relevance, purporting to M-cell translocatory, angiogenic and genotoxic properties [77]. Both avirulent and pathogenic strains of colonic E. coli are able to exert this genotoxic influence via outer membrane vesicles (OMVs) [78]. This is important as the colonisation of $E$. coli grown from colonic mucosa is a poor prognostic factor for colon cancer and it correlates with the TNM stage. Specifically, pathogenic cyclomodulin-positive E. coli strains are more prevalent on the mucosa of patients with stages III/IV than those with stage I colon cancer [79].

\section{Future perspectives: accounting for the complexity of the CRC microbiome}

As we have seen, the majority of existing research on the gut microbiota in CRC has fallen into two broad categories: (1) cataloguing exercises which seek to describe colonic ecological composition and thus make inferences about bacteria which may be over-represented in the disease state and (2) reductive science which identifies and thoroughly investigates (using in vitro and/or animal models) a particular bacterium (e.g. F. nucleatum) with putative pro-neoplastic capabilities. Both of these approaches have their drawbacks. The former, in the absence of complementary techniques such as metabolomics, fails to provide insights on microbiota function. The latter is likely to underestimate the complexity of the diverse microbial communities co-existing in the developing tumour micro-environment [80]. It is perhaps telling that F. nucleatum, the pathobiont which has aroused most attention in CRC, appears to be found in only 13\% of human CRCs [73]. Moreover, attempts to replicate the findings of earlier studies have demonstrated contradictory results regarding the prevalence and abundance of F. nucleatum in CRC [81].

In addition, concerns remain about the validity of existing findings in this field of research. Early studies suffered from a lack of consistency in sampling protocols, differing analytical methodologies and small numbers of patients. There was often a paucity of adequate clinical phenotyping data and an unrealistic supposition that polyps and CRCs are pathologically homogeneous. Although some of these issues are better addressed by contemporary studies $[82,83]$, the worry lingers that conclusions may be skewed by unappreciated confounding factors, including ethnicity, comorbidity and medication. Furthermore, it is probable that the circumstances in which samples are taken will also influence the ecological characteristics of the CRC microbiome and there remains considerable disagreement about the best methods for sampling the microbiota, with mucosal biopsies, stool and rectal swabs all providing differing information [84, 85]. Finally, the elephant in the room for all cancer microbiome studies is the issue of separating causation from association [86]. The solution to this problem has to include large, prospective, cohort studies with longitudinal sampling of participants prior to the development of the disease, a process that will take decades. The arguments in favour of this approach are being made ever more vociferously [87]. 


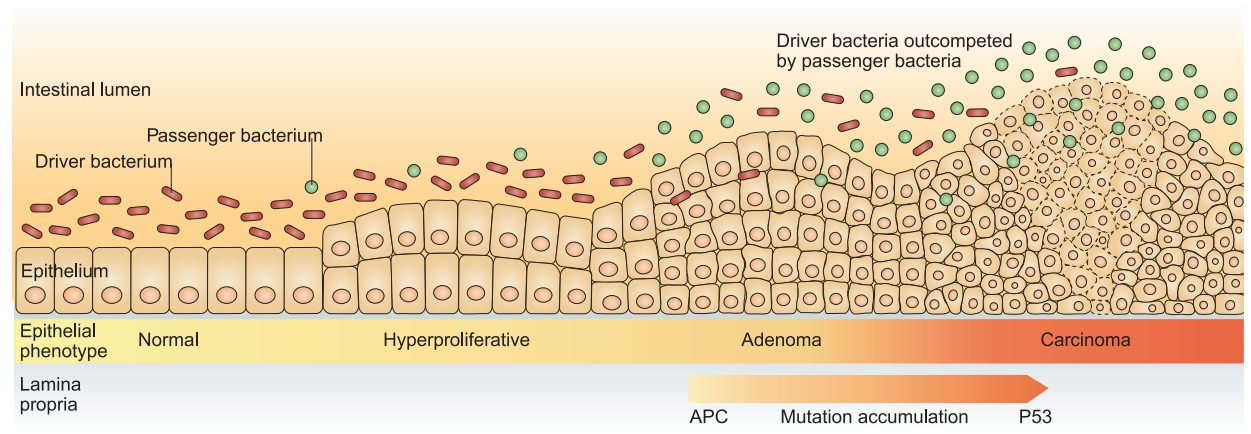

Figure 2. The driver-passenger model. Taken from 'A bacterial driver-passenger model for CRC: beyond the usual suspects'. Tjalsma et al [88] Nature Reviews Microbiology (2012).

Even with better human studies, given the enormous inter-individual variability and diversity of composition and function of the colonic microbiota, a more sophisticated analytical approach is clearly required. An attempt to conceptualise this complexity is provided by the driver-passenger model [88]. It postulates that genetically susceptible individuals might be colonised by a cocktail of pathogenic bacteria, which can cause inflammation, increase cell proliferation and produce genotoxic substrates, thus driving the initiation of early neoplastic lesions and contributing to the accumulation of genetic mutations as lesions progress (Figure 2). Furthermore, as the tumour develops, with associated changes in the metabolic milieu of the tumour microenvironment, these pathogenic driver species may be out-competed by opportunistic passengers, which thrive in the altered ecological niche. This model too is in all probability overly simplistic: perhaps, there are active passengers, which facilitate local invasion and distant metabolic spread.

Critically, it remains the case that the function and metabolic niche requirements of bacterial communities in diseases such as $\mathrm{CRC}$ are largely unknown. A range of 'omics' techniques are now being developed to address this knowledge shortfall [89]. These include metatranscriptomics and metaproteomics, which go some way to bridge the gap, but it is metabolomics, which seeks to identify and quantify all of the metabolites present in a sample, that emerges as the most suitable application to integrate with studies of the microbiome [90].

\section{Conclusion}

With advances in computational and systems medicine, investigators are producing novel insights into colonic gene-environment interactions [91] and data are now emerging suggesting that the colonic microbiota plays a vital symbiotic role in determining the metabolic milieu of the tumour micro-environment [92]. We now have the opportunity to mine extremely large parallel sets of clinical, epidemiological, dietary, pathological and omics data to streamline the direction of ongoing cancer and microbiome research. This approach has already borne fruit in the discipline of molecular pathological epidemiology [93, 94]. Future studies must integrate multi-omics human datasets and leverage their discoveries to guide relevant and suitably refined mechanistic investigation.

\section{Acknowledgments}

The authors would like to acknowledge funding from Imperial College Biomedical Research Centre, The Royal Marsden Biomedical Research Centre, Bowel and Cancer Research and Cancer Research UK.

\section{Conflicts of interest}

The authors declare that they have no conflicts of interest. 


\section{References}

1. Ferlay J, Steliarova-Foucher E, and Lortet-Tieulent J, et al (2013) Cancer incidence and mortality patterns in Europe: estimates for 40 countries in 2012 Eur J Cancer 49(6) 1374-1403 https://doi.org/10.1016/j.ejca.2012.12.027 PMID: 23485231

2. Bailey CE, Hu CY, and You YN, et al (2015) Increasing disparities in the age-related incidences of colon and rectal cancers in the United States, 1975-2010 JAMA Surg 150(1) 17-22 https://doi.org/10.1001/jamasurg.2014.1756 PMCID: 4666003

3. Center MM, Jemal A, and Smith RA, et al (2009) Worldwide variations in colorectal cancer CA Cancer J Clin 59(6) 366-378 https:// doi.org/10.3322/caac.20038 PMID: 19897840

4. Siegel RL, Fedewa SA, and Anderson WF, et al (2017) Colorectal cancer incidence patterns in the United States, 1974-2013 J Natl Cancer Inst 109(8) https://doi.org/10.1093/jnci/djw322 PMID: 29117389

5. Frank DN and Pace NR (2008) Gastrointestinal microbiology enters the metagenomics era Curr Opin Gastroenterol 24(1) 4-10 https://doi.org/10.1097/MOG.0b013e3282f2b0e8

6. Cho I and Blaser MJ (2012) The human microbiome: at the interface of health and disease Nat Rev Genet 13(4) 260-270 https:// doi.org/10.1038/nrg3182 PMID: 22411464 PMCID: 3418802

7. Arnold M, Sierra MS, and Laversanne M, et al (2017) Global patterns and trends in colorectal cancer incidence and mortality Gut 66(4) 683-691 https://doi.org/10.1136/gutjnl-2015-310912

8. Bray F and Soerjomataram I (2015) The changing global burden of cancer: transitions in human development and implications for cancer prevention and control Cancer: Disease Control Priorities 3rd edn vol 3 eds H Gelband, P Jha, and R Sankaranarayanan, et al (Washington, DC: The International Bank for Reconstruction and Development/The World Bank) pp 101-121

9. Taylor DP, Burt RW, and Williams MS, et al (2010) Population-based family history-specific risks for colorectal cancer: a constellation approach Gastroenterology 138(3) 877-885 https://doi.org/10.1053/j.gastro.2009.11.044 PMCID: 2831153

10. Cai S, Li Y, and Ding Y, et al (2014) Alcohol drinking and the risk of colorectal cancer death: a meta-analysis Eur J Cancer Prev 23(6) 532-539 https://doi.org/10.1097/CEJ.0000000000000076 PMID: 25170915

11. Wu AH, Paganini-Hill A, and Ross RK, et al (1987) Alcohol, physical activity and other risk factors for colorectal cancer: a prospective study Br J Cancer 55(6) 687-694 https://doi.org/10.1038/bjc.1987.140 PMID: 3620314 PMCID: 2002031

12. Botteri E, lodice S, and Bagnardi V, et al (2008) Smoking and colorectal cancer: a meta-analysis JAMA 300(23) 2765-2778 https:// doi.org/10.1001/jama.2008.839 PMID: 19088354

13. Frezza EE, Wachtel MS, and Chiriva-Internati M (2006) Influence of obesity on the risk of developing colon cancer Gut 55(2) 285-291 https://doi.org/10.1136/gut.2005.073163

14. Burkitt DP, Walker AR, and Painter NS (1972) Effect of dietary fibre on stools and the transit-times, and its role in the causation of disease Lancet (London, England) 2(7792) 1408-1412 https://doi.org/10.1016/S0140-6736(72)92974-1

15. Asano T and McLeod RS (2002) Dietary fibre for the prevention of colorectal adenomas and carcinomas Cochrane Database Syst Rev (2) Cd003430 PMID: 12076480

16. Yao Y, Suo T, and Andersson R, et al (2017) Dietary fibre for the prevention of recurrent colorectal adenomas and carcinomas Cochrane Database of Syst Rev 1 Cd003430

17. Bouvard V, Loomis D, and Guyton KZ, et al (2015) Carcinogenicity of consumption of red and processed meat Lancet Oncol 16(16) 1599-1600 https://doi.org/10.1016/S1470-2045(15)00444-1 PMID: 26514947 
18. Carr PR, Walter $\mathrm{V}$, and Brenner $\mathrm{H}$, et al (2016) Meat subtypes and their association with colorectal cancer: systematic review and meta-analysis Int J Cancer 138(2) 293-302 https://doi.org/10.1002/ijc.29423

19. Norat T, Aune D, and Chan D, et al (2014) Fruits and vegetables: updating the epidemiologic evidence for the WCRF/AICR lifestyle recommendations for cancer prevention Cancer Treat Res 159 35-50 https://doi.org/10.1007/978-3-642-38007-5 3

20. Gonzalez CA and Riboli E (2010) Diet and cancer prevention: contributions from the European Prospective Investigation into Cancer and Nutrition (EPIC) study Eur J Cancer 46(14) 2555-2562 https://doi.org/10.1016/j.ejca.2010.07.025 PMID: 20843485

21. Le Marchand L and Kolonel LN (1992) [Cancer in Japanese migrants to Hawaii: interaction between genes and environment] Rev Epidemiol Sante Publique 40(6) 425-430 PMID: 1287741

22. Houlston RS, Cheadle J, and Dobbins SE, et al (2010) Meta-analysis of three genome-wide association studies identifies susceptibility loci for colorectal cancer at 1q41, 3q26.2, 12q13.13 and 20q13.33 Nat Gen 42(11) 973-977 https://doi.org/10.1038/ ng.670

23. Figueiredo JC, Hsu L, and Hutter CM, et al (2014) Genome-wide diet-gene interaction analyses for risk of colorectal cancer PLoS Genet 10(4) e1004228 https://doi.org/10.1371/journal.pgen.1004228 PMID: 24743840 PMCID: 3990510

24. Koeth RA, Wang Z, and Levison BS, et al (2013) Intestinal microbiota metabolism of L-carnitine, a nutrient in red meat, promotes atherosclerosis Nat Med 19(5) 576-585 https://doi.org/10.1038/nm.3145 PMID: 23563705 PMCID: 3650111

25. Carbonero F, Benefiel AC, and Alizadeh-Ghamsari AH, et al (2012) Microbial pathways in colonic sulfur metabolism and links with health and disease Front Physio/ 3448 https://doi.org/10.3389/fphys.2012.00448 PMID: 23226130 PMCID: 3508456

26. Craciun S and Balskus EP (2012) Microbial conversion of choline to trimethylamine requires a glycyl radical enzyme Proc Natl Acad Sci U S A 109(52) 21307-21312 https://doi.org/10.1073/pnas.1215689109 PMID: 23151509 PMCID: 3535645

27. O'Neil CE, Zanovec M, and Cho SS, et al (2010) Whole grain and fiber consumption are associated with lower body weight measures in US adults: National Health and Nutrition Examination Survey 1999-2004 Nutr Res 30(12) 815-822 https://doi.org/10.1016/j.nutres.2010.10.013

28. Vipperla K and O'Keefe SJ (2012) The microbiota and its metabolites in colonic mucosal health and cancer risk Nutr Clin Pract 27(5) 624-635 https://doi.org/10.1177/0884533612452012 PMID: 22868282

29. Smith PM, Howitt MR, and Panikov N, et al (2013) The microbial metabolites, short-chain fatty acids, regulate colonic Treg cell homeostasis Science 341(6145) 569-573 https://doi.org/10.1126/science.1241165 PMID: 23828891 PMCID: 3807819

30. Bordonaro M, Lazarova DL, and Sartorelli AC (2008) Butyrate and Wnt signaling: a possible solution to the puzzle of dietary fiber and colon cancer risk? Cell Cycle 7(9) 1178-1183 https://doi.org/10.4161/cc.7.9.5818 PMID: 18418037

31. Donohoe DR, Collins LB, and Wali A, et al (2012) The Warburg effect dictates the mechanism of butyrate-mediated histone acetylation and cell proliferation Mol Cell 48(4) 612-626 https://doi.org/10.1016/j.molcel.2012.08.033 PMID: 23063526 PMCID: 3513569

32. Bultman SJ (2014) Molecular pathways: gene-environment interactions regulating dietary fiber induction of proliferation and apoptosis via butyrate for cancer prevention Clin Cancer Res 20(4) 799-803 https://doi.org/10.1158/1078-0432.CCR-13-2483 PMCID: 3944646

33. Zhu Q, Jin Z, and Wu W, et al (2014) Analysis of the intestinal lumen microbiota in an animal model of colorectal cancer PLoS One 9(6) e90849 https://doi.org/10.1371/journal.pone.0090849 PMID: 24603888 PMCID: 3946251

34. Wang T, Cai G, and Qiu Y, et al (2012) Structural segregation of gut microbiota between colorectal cancer patients and healthy volunteers ISME J 6(2) 320-329 https://doi.org/10.1038/ismej.2011.109 PMCID: 3260502 
35. Wu N, Yang X, and Zhang R, et al (2013) Dysbiosis signature of fecal microbiota in colorectal cancer patients Microb Ecol 66(2) 462-470 https://doi.org/10.1007/s00248-013-0245-9 PMID: 23733170

36. Ou J, Carbonero F, and Zoetendal EG, et al (2013) Diet, microbiota, and microbial metabolites in colon cancer risk in rural Africans and African Americans Am J Clin Nutr 98(1) 111-120 https://doi.org/10.3945/ajcn.112.056689 PMID: 23719549 PMCID: $\underline{3683814}$

37. O'Keefe SJ, Li JV, and Lahti L (2015) Fat, fibre and cancer risk in African Americans and rural Africans Nat Commun 66342 https://doi.org/10.1038/ncomms 7342

38. Mehta RS, Nishihara R, and Cao Y, et al (2017) Association of dietary patterns with risk of colorectal cancer subtypes classified by fusobacterium nucleatum in tumor tissue JAMA Oncol 3(7) 921-927 PMID: 28125762 PMCID: $\underline{502000}$

39. Biedermann L, Zeitz J, and Mwinyi J, et al (2013) Smoking cessation induces profound changes in the composition of the intestinal microbiota in humans PLoS One 8(3) e59260 https://doi.org/10.1371/journal.pone.0059260 PMID: 23516617 PMCID: 3597605

40. Opstelten JL, Plassais J, and van Mil SW, et al (2016) Gut microbial diversity is reduced in smokers with Crohn's disease Inflamm Bowel Dis 22(9) 2070-2077 https://doi.org/10.1097/MIB.0000000000000875 PMID: 27542127 PMCID: 4991341

41. Petriz BA, Castro AP, and Almeida JA, et al (2014) Exercise induction of gut microbiota modifications in obese, non-obese and hypertensive rats BMC Genomics 15511 https://doi.org/10.1186/1471-2164-15-511 PMID: 24952588 PMCID: 4082611

42. Clarke SF, Murphy EF, and O'Sullivan O, et al (2014) Exercise and associated dietary extremes impact on gut microbial diversity Gut 63(12) 1913-1920 https://doi.org/10.1136/gutjnl-2013-306541 PMID: 25021423

43. Bull-Otterson L, Feng W, and Kirpich I, et al (2013) Metagenomic analyses of alcohol induced pathogenic alterations in the intestinal microbiome and the effect of Lactobacillus rhamnosus GG treatment PLoS One 8(1) e53028 https://doi.org/10.1371/ journal.pone.0053028 PMID: 23326376 PMCID: 3541399

44. Cooper K, Squires H, and Carroll C, et al (2010) Chemoprevention of colorectal cancer: systematic review and economic evaluation Health Technol Assess 14(32) 1-206 https://doi.org/10.3310/hta14320

45. Lumeng CN and Saltiel AR (2011) Inflammatory links between obesity and metabolic disease J Clin Invest 121(6) 2111-2117 https://doi.org/10.1172/JCI57132 PMID: 21633179 PMCID: $\underline{3104776}$

46. Le Chatelier E, Nielsen T, and Qin J, et al (2013) Richness of human gut microbiome correlates with metabolic markers Nature 500(7464) 541-546 https://doi.org/10.1038/nature12506 PMID: 23985870

47. Li JV, Ashrafian $\mathrm{H}$, and Bueter M, et al (2011) Metabolic surgery profoundly influences gut microbial-host metabolic cross-talk Gut 60(9) 1214-1223 https://doi.org/10.1136/gut.2010.234708 PMID: 21572120 PMCID: 3677150

48. Palleja A, Kashani A, and Allin KH, et al (2016) Roux-en-Y gastric bypass surgery of morbidly obese patients induces swift and persistent changes of the individual gut microbiota Genome Med 8(1) 67 https://doi.org/10.1186/s13073-016-0312-1 PMID: 27306058 PMCID: 4908688

49. Ostlund MP, Lu Y, and Lagergren J (2010) Risk of obesity-related cancer after obesity surgery in a population-based cohort study Ann Surg 252(6) 972-976 https://doi.org/10.1097/SLA.0b013e3181e33778 PMID: 20571362

50. Tao W, Konings $\mathrm{P}$, and Hull MA, et al (2017) Colorectal cancer prognosis following obesity surgery in a population-based cohort study Obes Surg 27(5) 1233-1239 https://doi.org/10.1007/s11695-016-2431-6 PMCID: $\underline{5403840}$

51. Li JV, Reshat R, and Wu Q, et al (2011) Experimental bariatric surgery in rats generates a cytotoxic chemical environment in the gut contents Front Microbiol 2183 https://doi.org/10.3389/fmicb.2011.00183 PMID:21949514 PMCID: 3171674

52. Marshall BJ and Warren JR (1984) Unidentified curved bacilli in the stomach of patients with gastritis and peptic ulceration Lancet 1(8390) 1311-1315 https://doi.org/10.1016/S0140-6736(84)91816-6 PMID: 6145023 
53. Uemura N, Okamoto S, and Yamamoto S, et al (2001) Helicobacter pylori infection and the development of gastric cancer N Engl J Med 345(11) 784-789 https://doi.org/10.1056/NEJMoa001999 PMID: 11556297

54. Lowy DR and Schiller JT (2012) Reducing HPV-associated cancer globally Cancer Prev Res 5(1) 18-23 https://doi.org/10.1158/19406207.CAPR-11-0542

55. Honjo S, Srivatanakul $\mathrm{P}$, and Sriplung $\mathrm{H}$, et al (2005) Genetic and environmental determinants of risk for cholangiocarcinoma via Opisthorchis viverrini in a densely infested area in Nakhon Phanom, northeast Thailand Int J Cancer 117(5) 854-860 https://doi. org/10.1002/ijc.21146 PMID: 15957169

56. Lim MK, Ju YH, and Franceschi S, et al (2006) Clonorchis sinensis infection and increasing risk of cholangiocarcinoma in the Republic of Korea Am J Trop Med Hyg 75(1) 93-96 PMID: 16837714

57. Mostafa MH, Sheweita SA, and O'Connor PJ (1999) Relationship between schistosomiasis and bladder cancer Clin Microbiol Rev 12(1) 97-111 PMID: 9880476 PMCID: 88908

58. Sommer F and Backhed F (2013) The gut microbiota-masters of host development and physiology Nat Rev Microbiol 11(4) 227-238 https://doi.org/10.1038/nrmicro2974 PMID: 23435359

59. Sears CL and Pardoll DM (2011) Perspective: alpha-bugs, their microbial partners, and the link to colon cancer $J$ Infect Dis 203(3) 306-311 https://doi.org/10.1093/jinfdis/iiq061 PMID: 21208921 PMCID: 3071114

60. Marchesi JR, Dutilh BE, and Hall N, et al (2011) Towards the human colorectal cancer microbiome PLoS One 6(5) e20447 https://doi.org/10.1371/journal.pone.0020447 PMID: 21647227 PMCID: $\underline{3101260}$

61. Kostic AD, Chun E, and Robertson L, et al (2013) Fusobacterium nucleatum potentiates intestinal tumorigenesis and modulates the tumor-immune microenvironment Cell Host Microbe 14(2) 207-215 https://doi.org/10.1016/j.chom.2013.07.007 PMID: 23954159 PMCID: $\underline{3772512}$

62. Castellarin M, Warren RL, and Freeman JD, et al (2012) Fusobacterium nucleatum infection is prevalent in human colorectal carcinoma Genome Res 22(2) 299-306 https://doi.org/10.1101/gr.126516.111 PMCID: 3266037

63. McCoy AN, Araujo-Perez F, and Azcarate-Peril A, et al (2013) Fusobacterium is associated with colorectal adenomas PLoS One 8(1) e53653 https://doi.org/10.1371/journal.pone.0053653 PMID: 23335968 PMCID: $\underline{3546075}$

64. Wong SH, Kwong TNY, and Chow TC, et al (2017) Quantitation of faecal Fusobacterium improves faecal immunochemical test in detecting advanced colorectal neoplasia Gut 66(8) 1441-1448 https://doi.org/10.1136/gutjnl-2016-312766 PMCID: 5530471

65. Kostic AD, Gevers D, and Pedamallu CS, et al (2012) Genomic analysis identifies association of Fusobacterium with colorectal carcinoma Genome Res 22(2) 292-298 https://doi.org/10.1101/gr.126573.111 PMCID: $\underline{3266036}$

66. Eckburg PB, Bik EM, and Bernstein CN, et al (2005) Diversity of the human intestinal microbial flora Science 308(5728) 1635-1638 https://doi.org/10.1126/science.1110591 PMID: 15831718 PMCID: 1395357

67. Moore WE and Moore LV (2000) The bacteria of periodontal diseases Periodontology 5 66-77 https://doi.org/10.1111/ i.1600-0757.1994.tb00019.x

68. Rubinstein MR, Wang X, and Liu W, et al (2013) Fusobacterium nucleatum promotes colorectal carcinogenesis by modulating E-cadherin/beta-catenin signaling via its FadA adhesin Cell Host Microbe 14(2) 195-206 https://doi.org/10.1016/j.chom.2013.07.012 PMID: 23954158 PMCID: $\underline{3770529}$

69. Gur C, Ibrahim Y, and Isaacson B, et al (2015) Binding of the Fap2 protein of Fusobacterium nucleatum to human inhibitory receptor TIGIT protects tumors from immune cell attack Immunity 42(2) 344-355 https://doi.org/10.1016/.immuni.2015.01.010 PMID: 25680274 PMCID: 4361732 
70. Yang Y, Weng W, and Peng J, et al (2017) Fusobacterium nucleatum Increases Proliferation of Colorectal Cancer Cells and Tumor Development in Mice by Activating Toll-Like Receptor 4 Signaling to Nuclear Factor-kappaB, and Up-regulating Expression of MicroRNA-21 Gastroenterology 152(4) 851-866.e24 https://doi.org/10.1053/j.gastro.2016.11.018

71. Tahara T, Yamamoto E, and Suzuki H, et al (2014) Fusobacterium in colonic flora and molecular features of colorectal carcinoma Cancer Res 74(5) 1311-1318 https://doi.org/10.1158/0008-5472.CAN-13-1865 PMID: 24385213 PMCID: 4396185

72. Mima K, Sukawa Y, and Nishihara R, et al (2015) Fusobacterium nucleatum and T Cells in Colorectal Carcinoma JAMA Oncol 1(5) 653-661 https://doi.org/10.1001/jamaoncol.2015.1377 PMID: 26181352 PMCID: 4537376

73. Mima K, Nishihara R, and Qian ZR, et al (2016) Fusobacterium nucleatum in colorectal carcinoma tissue and patient prognosis Gut 65(12) 1973-1980 https://doi.org/10.1136/gutjnl-2015-310101 PMCID: $\underline{4769120}$

74. Bullman S, Pedamallu CS, and Sicinska E, et al (2017) Analysis of Fusobacterium persistence and antibiotic response in colorectal cancer Science 358(6369) 1443-1448 https://doi.org/10.1126/science.aal5240 PMID: 29170280 PMCID: 5823247

75. Kohoutova D, Smajs D, and Moravkova P, et al (2014) Escherichia coli strains of phylogenetic group B2 and D and bacteriocin production are associated with advanced colorectal neoplasia BMC Infect Dis 14733 https://doi.org/10.1186/s12879-014-0733-7 PMID: 25540872 PMCID: 4300055

76. Cougnoux A, Dalmasso G, and Martinez R, et al (2014) Bacterial genotoxin colibactin promotes colon tumour growth by inducing a senescence-associated secretory phenotype Gut 63(12) 1932-1942 https://doi.org/10.1136/gutjnl-2013-305257 PMID: $\underline{24658599}$

77. Prorok-Hamon M, Friswell MK, and Alswied A, et al (2014) Colonic mucosa-associated diffusely adherent afaC+ Escherichia coli expressing IpfA and pks are increased in inflammatory bowel disease and colon cancer Gut 63(5) 761-770 https://doi. org/10.1136/gutjnl-2013-304739 PMCID: $\underline{3995253}$

78. Tyrer PC, Frizelle FA, and Keenan JI (2014) Escherichia coli-derived outer membrane vesicles are genotoxic to human enterocyte-like cells Infect Agent Cancer 9(1) 2 https://doi.org/10.1186/1750-9378-9-2 PMID: 24405746 PMCID: 3898235

79. Bonnet M, Buc E, and Sauvanet P, et al (2014) Colonization of the human gut by E. coli and colorectal cancer risk Clin Cancer Res 20(4) 859-867 https://doi.org/10.1158/1078-0432.CCR-13-1343

80. Nakatsu G, Li X, and Zhou H, et al (2015) Gut mucosal microbiome across stages of colorectal carcinogenesis Nat Commun 6 8727 https://doi.org/10.1038/ncomms9727 PMID: 26515465 PMCID: 4640069

81. Repass J, Maherali N, and Owen K (2016) Registered report: fusobacterium nucleatum infection is prevalent in human colorectal carcinoma eLife 5 https://doi.org/10.7554/eLife.10012 PMID: 26882501 PMCID: 4764561

82. Flemer B, Lynch DB, and Brown JM, et al (2017) Tumour-associated and non-tumour-associated microbiota in colorectal cancer Gut 66(4) 633-643 https://doi.org/10.1136/qutjnl-2015-309595 PMCID: $\underline{529966}$

83. Peters BA, Dominianni C, and Shapiro JA, et al (2016) The gut microbiota in conventional and serrated precursors of colorectal cancer Microbiome 4(1) 69 https://doi.org/10.1186/s40168-016-0218-6

84. Araujo-Perez F, McCoy AN, and Okechukwu C, et al (2012) Differences in microbial signatures between rectal mucosal biopsies and rectal swabs Gut Microb 3(6) 530-535 https://doi.org/10.4161/gmic.22157

85. Budding AE, Grasman ME, and Eck A, et al (2014) Rectal swabs for analysis of the intestinal microbiota PLoS One 9(7) e101344 https://doi.org/10.1371/journal.pone.0101344 PMID: 25020051 PMCID: 4096398

86. Thomas RM and Jobin C (2015) The microbiome and cancer: is the 'oncobiome' mirage real? Trends Cancer 1(1) 24-35 https://doi.org/10.1016/j.trecan.2015.07.005 PMID: 26568984 PMCID: $\underline{4642279}$ 
87. Schmidt TSB, Raes J, and Bork P (2018) The human gut microbiome: from association to modulation Cell 172(6) 1198-1215 https://doi.org/10.1016/j.cell.2018.02.044 PMID: 29522742

88. Tjalsma H, Boleij A, and Marchesi JR, et al (2012) A bacterial driver-passenger model for colorectal cancer: beyond the usual suspects Nat Rev Microbiol 10(8) 575-582 https://doi.org/10.1038/nrmicro2819 PMID: 22728587

89. Lepage P, Leclerc MC, and Joossens M, et al (2013) A metagenomic insight into our gut's microbiome Gut 62(1) 146-158 https://doi.org/10.1136/gutjnl-2011-301805

90. Turnbaugh PJ and Gordon JI (2008) An invitation to the marriage of metagenomics and metabolomics Cell 134(5) 708-713 https://doi.org/10.1016/j.cell.2008.08.025 PMID: 18775300

91. Nicholson JK, Holmes E, and Kinross J, et al (2012) Host-gut microbiota metabolic interactions Science 336(6086) 1262-1267 https://doi.org/10.1126/science.1223813 PMID: 22674330

92. Kinross J, Mirnezami R, and Alexander J, et al (2017) A prospective analysis of mucosal microbiome-metabonome interactions in colorectal cancer using a combined MAS 1HNMR and metataxonomic strategy Sci Rep 7(1) 8979 https://doi.org/10.1038/ s41598-017-08150-3 PMID: 28827587 PMCID: $\underline{566496}$

93. Ogino S, Chan AT, and Fuchs CS, et al (2011) Molecular pathological epidemiology of colorectal neoplasia: an emerging transdisciplinary and interdisciplinary field Gut 60(3) 397-411 https://doi.org/10.1136/gut.2010.217182 PMCID: 3040598

94. Ogino S, Nowak JA, and Hamada T, et al (2018) Integrative analysis of exogenous, endogenous, tumour and immune factors for precision medicine Gut 67(6) 1168-1180 https://doi.org/10.1136/gutjnl-2017-315537 PMID: 29437869 PMCID: $\underline{5943183}$

95. Boleij $A$ and Tjalsma $H(2013)$ The itinerary of Streptococcus gallolyticus infection in patients with colonic malignant disease Lancet Infect Dis 13(8) 719-724 https://doi.org/10.1016/S1473-3099(13)70107-5 PMID: 23831427

96. Garza-Gonzalez E, Rios M, and Bosques-Padilla FJ, et al (2012) Immune response against Streptococcus gallolyticus in patients with adenomatous polyps in colon Int J Cancer 131(10) 2294-2299 https://doi.org/10.1002/ijc.27511 PMID: 22377818

97. Kumar R, Herold JL, and Schady D, et al (2017) Streptococcus gallolyticus subsp. gallolyticus promotes colorectal tumor development PLoS Pathog 13(7) e1006440 https://doi.org/10.1371/journal.ppat.1006440 PMID: 28704539 PMCID: 5509344

98. Wang X, Allen TD, and May RJ, et al (2008) Enterococcus faecalis induces aneuploidy and tetraploidy in colonic epithelial cells through a bystander effect Cancer Res 68(23) 9909-9917 https://doi.org/10.1158/0008-5472.CAN-08-1551 PMID: 19047172 PMCID: 2596646

99. Wang X, Yang Y, and Huycke MM (2015) Commensal bacteria drive endogenous transformation and tumour stem cell marker expression through a bystander effect Gut 64(3) 459-468 https://doi.org/10.1136/gutjnl-2014-307213 PMCID: $\underline{4345889}$

100. Cuevas-Ramos G, Petit CR, and Marcq I, et al (2010) Escherichia coli induces DNA damage in vivo and triggers genomic instability in mammalian cells Proc Natl Acad Sci U S A 107(25) 11537-11542 https://doi.org/10.1073/pnas.1001261107 PMID: 20534522 PMCID: 2895108

101. Maddocks OD, Scanlon KM, and Donnenberg MS (2013) An Escherichia coli effector protein promotes host mutation via depletion of DNA mismatch repair proteins mBio 4(3) e00152-13 https://doi.org/10.1128/mBio.00152-13 PMID: 23781066 PMCID: $\underline{3684829}$

102. Purcell RV, Pearson J, and Aitchison A, et al (2017) Colonization with enterotoxigenic Bacteroides fragilis is associated with early-stage colorectal neoplasia PLoS One 12(2) e0171602 https://doi.org/10.1371/journal.pone.0171602 PMID: 28151975 PMCID: $\underline{5289627}$

103. Goodwin AC, Destefano Shields CE, and Wu S, et al (2011) Polyamine catabolism contributes to enterotoxigenic Bacteroides fragilis-induced colon tumorigenesis Proc Natl Acad Sci U S A 108(37) 15354-15359 https://doi.org/10.1073/pnas.1010203108 PMID: 21876161 PMCID: $\underline{3174648}$ 
104.Wu S, Rhee KJ, and Albesiano E, et al (2009) A human colonic commensal promotes colon tumorigenesis via activation of T helper type 17 T cell responses Nat Med 15(9) 1016-1022 https://doi.org/10.1038/nm.2015 PMID: 19701202 PMCID: 3034219

105. Housseau F and Sears CL (2010) Enterotoxigenic Bacteroides fragilis (ETBF)-mediated colitis in Min (Apc+/-) mice: a human commensal-based murine model of colon carcinogenesis Cell Cycle 9(1) 3-5 https://doi.org/10.4161/cc.9.1.10352

106. Tsoi H, Chu ESH, and Zhang X, et al (2017) Peptostreptococcus anaerobius induces intracellular cholesterol biosynthesis in colon cells to induce proliferation and causes dysplasia in mice Gastroenterology 152(6) 1419-1433.e5 https://doi.org/10.1053/j. gastro.2017.01.009 PMID: 28126350

107.Erdman SE, Rao VP, and Poutahidis T, et al (2009) Nitric oxide and TNF-alpha trigger colonic inflammation and carcinogenesis in Helicobacter hepaticus-infected, Rag2-deficient mice Proc Natl Acad Sci U S A 106(4) 1027-1032 https://doi.org/10.1073/ pnas.0812347106 PMID: 19164562 PMCID: 2633549 